\title{
New Directions in Research on Aging
}

\author{
Andrzej Bartke ${ }^{1} \mathbb{D}$
}

Accepted: 10 November 2021 / Published online: 23 November 2021

(c) The Author(s), under exclusive licence to Springer Science+Business Media, LLC, part of Springer Nature 2021

\begin{abstract}
Biology of aging is an active and rapidly expanding area of biomedical research. Over the years, focus of work in this field has been gradually shifting from studying the effects and symptoms of aging to searching for mechanisms of the aging process. Progress of this work led to an additional shift from looking for "the mechanism" of aging and formulating the corresponding "theories of aging" to appreciation that aging represents a net result of multiple physiological changes and their intricate interactions. It was also shown that mechanisms of aging include nutrient-dependent signaling pathways which have been remarkably conserved in the course of the evolution. Another important development in this field is increased emphasis on searching for pharmacological and environmental interventions that can extend healthspan or influence other aspects of aging. Progress in understanding the key role of aging as a risk factor for chronic disease provides impetus for these studies. Data from the recent pandemic provided additional evidence for the impact of age on resilience. Progress of work in this area also was influenced by major analytical and technological advances, including greatly improved methods for the study of gene expression, protein, lipids, and metabolites profiles, enhanced ability to produce various genetic modifications and novel approaches to assessment of biological age. Progress in research on the biology of aging provides reasons for optimism about the chances that safe and widely applicable anti-aging interventions with significant benefits for both individual and public health will be developed in the not too distant future.
\end{abstract}

Keywords Aging $\cdot$ Geroscience $\cdot$ Healthspan $\cdot$ Lifespan $\cdot$ Interventions

\section{Introduction}

Biology of aging is a rapidly expanding and evolving research field, and we thought that the readers might be interested in a brief overview of new developments, new concepts, new areas of emphasis, and new methodological approaches in this area of investigation. What follows is a somewhat personal view of these changes during the last 25 years. Twenty-five years ago, Holly Brown-Borg reported remarkable extension of longevity of mutant mice we were working with [1], and the direction of research in our laboratory started to shift from reproductive endocrinology to biology of aging. For readers interested in earlier developments in this field and in another perspective on more recent

Andrzej Bartke

abartke@ siumed.edu

1 Department of Internal Medicine, Southern Illinois University School of Medicine, 801 N. Rutledge St., P. O.

Box 19628, Springfield, IL 62794-9628, USA events, we recommend an excellent recent article by Arlan Richardson [2].

\section{Genetics of Aging: Longevity Genes, Gene Polymorphisms, and Profiles of Gene Expression}

Pioneering studies of Johnson, Jazwinski, Kenyon, Guarente, Ruvkun, Partridge, Tatar, and other investigators in the ' $80 \mathrm{~s}$ and ' 90 s, provided evidence that mutations of individual genes can markedly, often quite impressively, extend longevity in different organisms, including baker's yeast (Saccharomyces cerevisiae), microscopic roundworm (Caenorhabditis elegans), and fruit fly (Drosophila melanogaster). These mutations were soon termed "longevity genes" or "longevity assurance genes," and their discovery attracted great attention within, as well as outside, the field of biology of aging, including popular news media. Studies of longevity genes in yeast and in invertebrate animals were soon followed by the reports that single gene mutations can also extend longevity in mice (Mus musculus) [1,3], organisms taxonomically and biologically much closer to humans. These findings in 
experimental animals led to renewed interest in the study of the genetic control of human aging and to search for longevity genes in individuals who lived to exceptionally old age (for example, centenarians) or came from long-lived families [4-8].

The most exciting outcomes of the studies of genetics of aging in the ' 90 s and in the succeeding years were the identification of specific cellular processes (signaling pathways) and the corresponding epistatic relationships between longevity genes, which are involved in the control of longevity, and the realization that these pathways have been remarkably preserved in the course of evolution [9-13]. Extensive homologies of the insulin/insulin-like growth factors signaling (IIS) pathway and the mechanistic target of rapamycin (mTOR) pathway [14, 15], and magnitude of their impact on aging in yeast, worms, insects, and mammals, are particularly striking when viewed in light of tremendous differences in body plan, life history, and physiological functioning of these species.

Long-lived mutants have been extremely useful in the studies of mechanisms of aging because their complex phenotypes and extended longevity can be traced back to functions of individual genes, and animals predisposed to slower and/or delayed aging can be easily identified when they are young, thus avoiding complications due to the effects of aging and to shorter survival of normal controls. While these studies continue, the focus of work on the genetics of aging has been gradually shifting from the search for novel longevity genes and single nucleotide polymorphisms (SNPs) associated with longevity, risk of various chronic diseases, or other age-related phenotypes, to characterizing changes in gene expression and corresponding changes in function of various tissues and organ systems. In terms of methodology, this represents a shift away from genome-wide association studies (GWAS) to various microarray platforms for analysis of steady-state levels of messenger RNAs, RNA sequencing (RNAseq), and now increasingly to single-cell RNA sequencing (scRNA-seq). There is also increasing interest in chromatin modifications (primarily acetylation and methylation) that may be involved in epigenetic control of gene expression.

\section{Healthspan Vs Lifespan}

Alterations in average, median, and particularly in the maximal longevity, provide important and, in most cases, uncontestable evidence of the effects of genetic factors, environment, or pharmacological interventions on the process of aging. Real or imagined possibilities of extending lifespan have been sought for millennia and continue to excite our imagination. However, reflection on the issues of aging, mortality, and longevity, leads to realization that in terms of both public health issues and individual hopes and aspirations, longevity per se is not the key parameter or the most important goal. Instead, there is increasing interest in achieving "healthy aging" or "successful aging," with these terms representing extension of healthspan, the period of life free of disease and disabilities. This brings up a question whether any of the interventions shown to extend longevity (such as calorie restriction, suppression of somatotropic signaling, or treatment with rapamycin) can also increase the absolute or relative length of the healthspan. This question appears to be very straightforward, but is not easy to answer. Much work has been done, and continues to be directed at developing reliable and practical means of assessment of healthspan and frailty in humans and in experimental animals [16-21].

The importance of this issue is almost impossible to overstate. This is probably best illustrated by the association of the impressive increase in human life expectancy due to vaccinations and other public health measures and to the progress of medicine with the increased number of people living with Alzheimer's disease and other dementias. On the other hand, people achieving exceptional longevity generally experienced a reduced, rather than expanded, period of major health problems and dependence [22-27]. Moreover, there is increasing evidence that anti-aging interventions can extend healthspan in experimental animals [3, 28-31]. These findings provide realistic hope that nutritional, pharmacological, or environmental interventions can "square the survival curve" that is prolong healthy life and reduce the period of frailty, morbidity, infirmity, and dependence [32].

\section{Translating Research Findings from Experimental Animals to Humans; Anti-Aging Interventions as Preventive Medicine}

Effects of various regimens of dietary restriction reported decades ago provided clear evidence that reducing caloric intake or restricting intake of protein or essential amino acids can extend longevity and delay the onset, as well as the incidence, of age-related diseases in many organisms. Surprisingly, until recently, the enormous potential of anti-aging interventions as a bona fide preventive medicine received little attention from the medical profession or public health sector. The relatively recent increase in the interest in this subject led to the formulation of the "geroscience" concept [33], which represents recognition of the biological process of aging as a modifiable risk factor for chronic diseases. Chronological age is well documented to represent a key risk factor for cardiovascular disease, Alzheimer's disease and other dementias, arthritis, diabetes, and cancer. The disproportional impact of the Covid-19 pandemic on the elderly focused attention on the role of aging in susceptibility to infections and ability to recover from illness. 
Renewed appreciation of the relationships between aging and disease promotes search for interventions that could be recommended to healthy individuals in an effort to extend their healthspan. Drugs which are already well characterized and approved for human use and compounds sold without a prescription are of obvious interest in this regard. Metformin is a drug widely used for the treatment of diabetes and has very strong record of safety and effectiveness. It was already reported to provide treated patients with significant level of protection from cancer, CVD, and dementias [34-36], and was shown to extend longevity of mice in some (although not all) studies [37-42]. A search for potential health benefits of metformin in individuals who do not have diabetes was spearheaded by Barzilai and his colleagues and a study termed "TAME" (Targeting Aging with Metformin) is ongoing [43].

Rapamycin inhibits RNA translation and protein synthesis, and promotes autophagy by suppressing the activity of mTOR Complex I and is used clinically to prevent rejection of transplanted organs [44]. It extends longevity in mice and in simpler organisms ([45-51], and was reported to prevent cancer [52]. Moreover, a closely related compound was reported to improve the responses of middle-aged people to a flu vaccine [53]. The impact of rapamycin on aging, with particular attention to healthspan, is tested in ongoing studies in domestic dogs [54] and non-human primates [55].

Another relatively new area of biogerontological studies deals with the role of senescent cells. Cell senescence was long believed to represent a natural defense against cancer by removing the cells from dividing (mitotic) population [56]. However it was later realized that accumulation of senescent cells paradoxically leads to degradation of tissue environment, including increased risk of developing cancer [57]. Studies of Kirkland, van Deursen, Campisi, Niedernhofer, Robbins, and others provided evidence that drugs capable of reducing the accumulation of senescent cells can extend longevity, ameliorate numerous effects of aging, and prevent age-related disease in mice [58-62]. A number of clinical studies on the effects of these drugs (termed "senolytics") in various human cohorts are ongoing and results obtained to date are encouraging [63-65].

\section{New Methods, New Concepts, and New Vocabulary}

Rapid progress in the fields of molecular and cell biology is continuing at an ever-accelerating pace and creates new opportunities for the studies of aging. The resulting shifts in emphasis include increasing interest in RNA-Seq and scRNA-seq (as mentioned earlier in this article) along with studies of the downstream consequences of alterations in gene expression which include analysis of proteins, metabolites, lipids, and inflammation markers (proteomics, metabalomoics, lipidomics etc).
Another important recent development was the demonstration that various measures of DNA methylation correlate with chronological age with great (often astounding) precision, thus providing "aging clocks." It appears that age-related modifications of DNA and histones may provide the long-sought biomarkers of aging. Importantly, there is increasing evidence that age assessed by these clocks is influenced by factors known or suspected to affect the rate of aging such as stress, disease, anti-aging interventions, and life-extending mutations [66-70]. This indicates that the aging clocks can provide meaningful assessment of biological age. This will likely prove very useful in screening potential anti-aging interventions and predicting risk of chronic disease and death.

In addition to the impressive methodological progress in the studies of biology of aging, there are also important developments in the interpretation of data and conceptual implications of the accumulating information. Thus there is increasing appreciation that aging cannot be explained in terms of a single definable cause (as proposed by the various "theories of aging" that have been proposed over the years) because it reflects complex network of interactions between various mechanisms operating more or less concomitantly. A popular representation of this conceptual advance is a graphic image of a set of hallmarks or pillars of aging and their interconnections [71, 72]. Although strict reliance on this model of the mechanism(s) of aging has recently been questioned [73], it certainly provides a very useful emphasis on the complexity of the underpinning physiological interactions and the difficulties in unravelling its specific elements.

Another, less often discussed difficulty in identifying mechanisms of aging, concerns discerning the mechanisms from the effects of aging. This is further complicated by many age-associated alterations representing effects of aging (such as progressive decline of insulin sensitivity or thermogenic activity of brown adipose tissue) appear to be also causally related to the aging process [74-77].

\section{Novel Mechanisms and Prospects for Novel Interventions}

Novel, often unsuspected mechanisms, regulatory loops, and means of cross-talk between different tissues that can influence longevity are identified with surprising frequency. The relatively recent appreciation of the role of cell senescence in organismal aging followed by identification of compounds that deplete senescent cells were mentioned earlier in this article.

Remarkable extension of longevity in mice in which experimentally-induced increase in vascular endothelial growth factor (VEGF) produced apparent vascular rejuvenation was described earlier this year [78]. These exciting 
findings suggests existence of yet another potentially "druggable" mechanism involved in the control of aging.

Studies of various classes of non-coding RNA [79-84], NLRP 3 inflammasome [85-89], and hepatic production of hydrogen sulfide [90-92] provide other examples of fairly recent developments in the search for mechanisms of aging and anti-aging interventions.

\section{Increasing Emphasis on the Importance of Genetic Background of Experimental Animals in Generating Data Potentially Translatable to Humans and on Sex Differences in Responses to Anti-Aging Interventions}

Advantages of using inbred (that is genetically almost identical) experimental animals in biomedical research include wealth of information from earlier studies, multiple commercial sources, availability of genetically modified animals with the same genetic background, and a somewhat questionable expectation of reduced variability. This, combined with the understandable tendency to use the same type of animals that have been used in published studies, led to the popularity of C57BL6 mice in research on aging. However, increased emphasis on the importance of "translatability" of animal research data to human applications led to interest in using animals with genetic architecture resembling normal human populations, not inbred and highly variable. To meet this need, Miller suggested using animals derived from crossing four relatively genetically unrelated inbred strains, the UMHET3 mice. Notably, UMHET3 mice are currently used in the Interventions Testing Program (ITP) of the National Institute of Aging. This program tests compounds suspected of anti-aging activity on longevity of mice at three different sites (in Michigan, Texas, and Massachusetts) and reports both positive and negative findings in peerreviewed literature [93] (https://www.nia.nih.gov/research/ dab/interventions-testing-program-itp/publications-nia-inter ventions-testing-program). Intriguingly, ITP results provided novel evidence for the impact of local environmental factors on the outcome of longevity studies. Longevity of UMHET3 mice is not identical at the three research sites in spite of extraordinary effort to control uniformity of diet, housing conditions, ambient temperature, etc. [94].

Another type of genetically heterogeneous (Diversity Outbred; DO) mice for aging studies was developed at the Jackson Laboratory in Maine (https://www.jax.org/ strain/009376). Diversity Outbred mice were developed by random outcross matings of 160 Collaborative Cross recombinant inbred mouse lines, and the colony is maintained by continued random matings that avoid crosses between siblings. This colony maintenance strategy retains the widest possible genetic diversity in each DO mouse.
The DO parental lines, the Collaborative Cross strains, were developed by crossing eight inbred mouse strains, followed by subsequent inbreeding to produce new and unique recombinant incipient inbred lines [95].

Because of the concern that female reproductive cycles may introduce an additional source of individual variability, most of older studies published in this area utilized only males. In accordance with guidelines from the National Institutes of Health and policies of many biomedical journals, newer work frequently utilizes both sexes. This led to the demonstration that results obtained in males and females are rarely identical and often strikingly different. For example, ITP studies identified a number of interventions that extend longevity only in one sex ( $17 \alpha$ Estradiol and Nordihydroguaiaretic acid) or have a much greater effect in females (rapamycin) or males (aspirin, acarbose and Protandim $\left.{ }^{\circledR}\right)$ [96-98].

\section{Conclusions}

Focus of studies on the biology of aging has gradually shifted from describing the multiple effects of aging to the search for genetic and cellular mechanisms of aging. This resulted in identification of multiple mutations and deletions that impact aging, single nucleotide polymorphisms that track longevity, and several cellular signaling pathways with a remarkably conserved role in aging in evolutionarily very distant organisms.

Much of the ongoing work is directed at finding interventions that could have beneficial impact on human aging, with particular emphasis on extending the healthspan. There is much hope that nutritional, lifestyle, and pharmacological anti-aging interventions will emerge as key methods of preventative medicine with potentially enormous impact on individual welfare and public health.

Acknowledgements We apologize to those whose work pertinent to the issues discussed was not cited due to limitations of the format or to inadvertent omissions. We are grateful for editorial assistance provided by Lisa Hensley. This work was supported by the American Diabetes Association grant ADA 1-19-IBS-126 and National Institutes of Health [NIA R21AG062985].

Data Availability N/A

Code Availability N/A

Author Contributions Concept, writing, funding - A. Bartke.

Funding This work was supported by the American Diabetes Association grant ADA 1-19-IBS-126 and National Institutes of Health [NIA R21AG062985]. 


\section{Declarations}

Conflicts of Interest/Competing Interests A. Bartke has nothing to disclose.

\section{Ethics Approval N/A}

Consent to Participate N/A

Consent for Publication N/A

\section{References}

1. Brown-Borg, H. M., Borg, K. E., Meliska, C. J., et al. (1996). Dwarf mice and the ageing process. Nature, 384(6604), 33. https://doi.org/10.1038/384033a0

2. Richardson, A. (2021). You have come a long way baby: Five decades of research on the biology of aging from the perspective of a researcher studying aging. The Journals of Gerontology. Series A, Biological Sciences and Medical Sciences, 76(1), 57-63. https:// doi.org/10.1093/gerona/glaa208

3. Bartke, A. (2011). Single-gene mutations and healthy ageing in mammals. Philosophical Transactions of the Royal Society of London. Series B, Biological Sciences, 366(1561), 28-34. https://doi. org/10.1098/rstb.2010.0281

4. De Benedictis, G., Tan, Q., Jeune, B., et al. (2001). Recent advances in human gene-longevity association studies. Mechanisms of Ageing and Development, 122(9), 909-920.

5. Suh, Y., Atzmon, G., Cho, M. O., et al. (2008). Functionally significant insulin-like growth factor I receptor mutations in centenarians. Proceedings of the National Academy of Sciences of the United States of America, 105(9), 3438-3442. https://doi.org/10. 1073/pnas.0705467105

6. Bae, H., Gurinovich, A., Malovini, A., et al. (2017). Effects of FOXO3 polymorphisms on survival to extreme longevity in four centenarian studies. The Journals of Gerontology. Series A, Biological Sciences and Medical Sciences. https://doi.org/10.1093/ gerona/glx 124

7. Zeng, Y., Nie, C., Min, J., et al. (2018). Sex differences in genetic associations with longevity. JAMA Network Open, 1(4), e181670. https://doi.org/10.1001/jamanetworkopen.2018.1670

8. Sebastiani, P., Gurinovich, A., Nygaard, M., et al. (2019). APOE alleles and extreme human longevity. The Journals of Gerontology. Series A, Biological Sciences and Medical Sciences, 74(1), 44-51. https://doi.org/10.1093/gerona/gly174

9. Kimura, K. D., Tissenbaum, H. A., Liu, Y., et al. (1997). Daf-2, an insulin receptor-like gene that regulates longevity and diapause in Caenorhabditis elegans. Science, 277(5328), 942-946. https:// doi.org/10.1126/science.277.5328.942

10. Tissenbaum, H. A., \& Ruvkun, G. (1998). An insulin-like signaling pathway affects both longevity and reproduction in Caenorhabditis elegans. Genetics, 148(2), 703-717.

11. Longo, V. D., \& Finch, C. E. (2003). Evolutionary medicine: From dwarf model systems to healthy centenarians? Science, 299(5611), 1342-1346.

12. Tatar, M., Bartke, A., \& Antebi, A. (2003). The endocrine regulation of aging by insulin-like signals. Science, 299, 1346-1351.

13. McElwee, J. J., Schuster, E., Blanc, E., et al. (2007). Evolutionary conservation of regulated longevity assurance mechanisms. Genome Biology, 8(7), R132. https://doi.org/10.1186/ gb-2007-8-7-r132

14. McCormick, M. A., Tsai, S. Y., \& Kennedy, B. K. (2011). TOR and ageing: A complex pathway for a complex process.
Philosophical Transactions of the Royal Society of London. Series B, Biological Sciences, 366(1561), 17-27. https://doi.org/10.1098/ rstb.2010.0198

15. Johnson, S. C., Sangesland, M., Kaeberlein, M., et al. (2015). Modulating mTOR in aging and health. Interdisciplinary Topics in Gerontology, 40, 107-127. https://doi.org/10.1159/000364974

16. Burn, R., Hubbard, R. E., Scrase, R. J., et al. (2018). A frailty index derived from a standardized comprehensive geriatric assessment predicts mortality and aged residential care admission. BMC Geriatrics, 18(1), 319. https://doi.org/10.1186/ s12877-018-1016-8

17. Heinze-Milne, S. D., Banga, S., \& Howlett, S. E. (2019). Frailty assessment in animal models. Gerontology, 65(6), 610-619. https://doi.org/10.1159/000501333

18. Huffman, D. M., Justice, J. N., Stout, M. B., et al. (2016). Evaluating health span in preclinical models of aging and disease: Guidelines, challenges, and opportunities for Geroscience. The Journals of Gerontology. Series A, Biological Sciences and Medical Sciences, 71(11), 1395-1406. https://doi.org/10.1093/gerona/glw106

19. Bellantuono, I., de Cabo, R., Ehninger, D., et al. (2020). A toolbox for the longitudinal assessment of healthspan in aging mice. Nature Protocols, 15(2), 540-574. https://doi.org/10.1038/ s41596-019-0256-1

20. Bisset, E. S., \& Howlett, S. E. (2019). The biology of frailty in humans and animals: Understanding frailty and promoting translation. AGING MEDICINE, 2(1), 27-34. https://doi.org/10.1002/ agm2.12058

21. Richardson, A., Fischer, K. E., Speakman, J. R., et al. (2015). Measures of Healthspan as indices of aging in mice-A recommendation. The Journals of Gerontology: Series A, 71(4), 427430. https://doi.org/10.1093/gerona/glv080

22. Schoenhofen, E. A., Wyszynski, D. F., Andersen, S., et al. (2006). Characteristics of 32 supercentenarians. Journal of the American Geriatrics Society, 54(8), 1237-1240. https://doi.org/10.1111/j. 1532-5415.2006.00826.x

23. Atzmon, G., Schechter, C., Greiner, W., et al. (2004). Clinical phenotype of families with longevity. Journal of the American Geriatrics Society, 52(2), 274-277.

24. Sebastiani, P., Sun, F. X., Andersen, S. L., et al. (2013). Families enriched for exceptional longevity also have increased healthspan: Findings from the long life family study. Frontiers in Public Health, 1, 38. https://doi.org/10.3389/fpubh.2013.00038

25. Adams, E. R., Nolan, V. G., Andersen, S. L., et al. (2008). Centenarian offspring: Start healthier and stay healthier. Journal of the American Geriatrics Society, 56(11), 2089-2092. https://doi.org/ 10.1111/j.1532-5415.2008.01949.x

26. Westendorp, R. G., van Heemst, D., Rozing, M. P., et al. (2009). Nonagenarian siblings and their offspring display lower risk of mortality and morbidity than sporadic nonagenarians: The Leiden longevity study. Journal of the American Geriatrics Society, 57(9), 1634-1637. https://doi.org/10.1111/j.1532-5415.2009. 02381.x

27. Wijsman, C. A., Rozing, M. P., Streefland, T. C., et al. (2011). Familial longevity is marked by enhanced insulin sensitivity. Aging Cell, 10(1), 114-121. https://doi.org/10.1111/j.1474-9726. 2010.00650.x

28. Folch, J., Busquets, O., Ettcheto, M., et al. (2018). Experimental models for aging and their potential for novel drug discovery. Current Neuropharmacology, 16(10), 1466-1483. https://doi.org/10. 2174/1570159X15666170707155345

29. Acosta-Rodríguez, V. A., Rijo-Ferreira, F., Green, C. B., et al. (2021). Importance of circadian timing for aging and longevity. Nature Communications, 12(1), 2862. https://doi.org/10.1038/ s41467-021-22922-6

30. de Cabo, R., Carmona-Gutierrez, D., Bernier, M., et al. (2014). The search for Antiaging interventions: From elixirs to fasting 
regimens. Cell, 157(7), 1515-1526. https://doi.org/10.1016/j.cell. 2014.05.031

31. Lee, M. B., \& Kaeberlein, M. (2018). Translational geroscience: From invertebrate models to companion animal and human interventions. Translational Medicine of Aging, 2, 15-29. https://doi. org/10.1016/j.tma.2018.08.002

32. Ros, M., \& Carrascosa, J. M. (2020). Current nutritional and pharmacological anti-aging interventions. Biochimica et Biophysica Acta (BBA)-Molecular Basis of Disease, 1866(3), 165612. https:// doi.org/10.1016/j.bbadis.2019.165612

33. Sierra, F. (2016). The emergence of Geroscience as an interdisciplinary approach to the enhancement of health span and life span. Cold Spring Harbor Perspectives in Medicine, 6(4), a025163. https://doi.org/10.1101/cshperspect.a025163

34. Campbell, J. M., Stephenson, M. D., de Courten, B., et al. (2018). Metformin use associated with reduced risk of dementia in patients with diabetes: A systematic review and Meta-analysis. Journal of Alzheimer's Disease, 65(4), 1225-1236. https://doi. org/10.3233/JAD-180263

35. Valencia, W. M., Palacio, A., Tamariz, L., et al. (2017). Metformin and ageing: Improving ageing outcomes beyond glycaemic control. Diabetologia, 60(9), 1630-1638. https://doi.org/10.1007/ s00125-017-4349-5

36. Wang, C. P., Lorenzo, C., Habib, S. L., et al. (2017). Differential effects of metformin on age related comorbidities in older men with type 2 diabetes. Journal of Diabetes and its Complications, 31(4), 679-686. https://doi.org/10.1016/j.jdiacomp.2017.01.013

37. Martin-Montalvo, A., Mercken, E. M., Mitchell, S. J., et al. (2013). Metformin improves healthspan and lifespan in mice. Nature Communications, 4, 2192. https://doi.org/10.1038/ncomm s3192

38. Anisimov, V. N., Berstein, L. M., Popovich, I. G., et al. (2011). If started early in life, metformin treatment increases life span and postpones tumors in female SHR mice. Aging, 3(2), 148-157. https://doi.org/10.18632/aging.100273

39. Anisimov, V. N., Piskunova, T. S., Popovich, I. G., et al. (2010). Gender differences in metformin effect on aging, life span and spontaneous tumorigenesis in 129/Sv mice. Aging (Albany NY), 2(12), 945-958. https://doi.org/10.18632/aging.100245

40. Anisimov, V. N., Berstein, L. M., Egormin, P. A., et al. (2008). Metformin slows down aging and extends life span of female SHR mice. Cell Cycle, 7(17), 2769-2773. https://doi.org/10.4161/cc.7. 17.6625

41. Strong, R., Miller, R. A., Antebi, A., et al. (2016). Longer lifespan in male mice treated with a weakly estrogenic agonist, an antioxidant, an alpha-glucosidase inhibitor or a Nrf2-inducer. Aging Cell, 15(5), 872-884. https://doi.org/10.1111/acel.12496

42. Palliyaguru, D. L., Minor, R. K., Mitchell, S. J., et al. (2020). Combining a high dose of metformin with the SIRT1 activator, SRT1720, reduces life span in aged mice fed a high-fat diet. The Journals of Gerontology. Series A, Biological Sciences and Medical Sciences, 75(11), 2037-2041. https://doi.org/10.1093/gerona/ glaa148

43. Barzilai, N., Crandall, J. P., Kritchevsky, S. B., et al. (2016). Metformin as a tool to target aging. Cell Metabolism, 23(6), 10601065. https://doi.org/10.1016/j.cmet.2016.05.011

44. McMahon, G., Weir, M. R., Li, X. C., et al. (2011). The evolving role of mTOR inhibition in transplantation tolerance. Journal of the American Society of Nephrology, 22(3), 408. https://doi.org/ 10.1681/ASN.2010040351

45. Miller, R. A., Harrison, D. E., Astle, C. M., et al. (2010). Rapamycin, but not resveratrol or simvastatin, extends life span of genetically heterogeneous mice. The Journals of Gerontology: Series A, 66A(2), 191-201. https://doi.org/10.1093/gerona/glq178

46. Fok, W. C., Chen, Y., Bokov, A., et al. (2014). Mice fed rapamycin have an increase in lifespan associated with major changes in the liver transcriptome. PLoS One, 9(1), e83988. https://doi. org/10.1371/journal.pone.0083988

47. Bjedov, I., Toivonen, J. M., Kerr, F., et al. (2010). Mechanisms of life span extension by rapamycin in the fruit fly Drosophila melanogaster. Cell Metabolism, 11(1), 35-46. https://doi.org/ 10.1016/j.cmet.2009.11.010

48. Kaeberlein, M., Burtner, C. R., \& Kennedy, B. K. (2007). Recent developments in yeast aging. PLoS Genetics, 3(5), e84. https://doi.org/10.1371/journal.pgen.0030084

49. Robida-Stubbs, S., Glover-Cutter, K., Lamming, D. W., et al. (2012). TOR signaling and rapamycin influence longevity by regulating SKN-1/Nrf and DAF-16/FoxO. Cell Metabolism, 15(5), 713-724. https://doi.org/10.1016/j.cmet.2012.04.007

50. Powers 3rd, R. W., Kaeberlein, M., Caldwell, S. D., et al. (2006). Extension of chronological life span in yeast by decreased TOR pathway signaling. Genes \& Development, 20(2), 174-184. https://doi.org/10.1101/gad.1381406

51. Harrison, D. E., Strong, R., Sharp, Z. D., et al. (2009). Rapamycin fed late in life extends lifespan in genetically heterogeneous mice. Nature, 460(7253), 392-395. https://doi.org/10.1038/ nature 08221

52. Huang, S., Bjornsti, M. A., \& Houghton, P. J. (2003). Rapamycins: Mechanism of action and cellular resistance. Cancer Biology \& Therapy, 2(3), 222-232. https://doi.org/10.4161/cbt.2.3.360

53. Mannick, J. B., Morris, M., Hockey, H. P., et al. (2018). TORC1 inhibition enhances immune function and reduces infections in the elderly. Sci Transl Med, 10(449). doi: https://doi.org/10.1126/scitr anslmed.aaq1564.

54. Kaeberlein, M., Creevy, K. E., \& Promislow, D. E. L. (2016). The dog aging project: Translational geroscience in companion animals. Mammalian genome : official journal of the International Mammalian Genome Society, 27(7-8), 279-288. https://doi.org/ 10.1007/s00335-016-9638-7

55. Salmon, A. (2019). Intervention with rapamycin to improve healthy aging and longevity in a non-human primate. Innovation in Aging, 3, S108-S108. https://doi.org/10.1093/geroni/igz038. 403

56. Serrano, M., Lin, A. W., McCurrach, M. E., et al. (1997). Oncogenic ras provokes premature cell senescence associated with accumulation of p53 and p16INK4a. Cell, 88(5), 593-602. https:// doi.org/10.1016/s0092-8674(00)81902-9

57. Davalos, A. R., Coppe, J. P., Campisi, J., et al. (2010). Senescent cells as a source of inflammatory factors for tumor progression. Cancer Metastasis Reviews, 29(2), 273-283. https://doi.org/10. 1007/s10555-010-9220-9

58. Xu, M., Pirtskhalava, T., Farr, J. N., et al. (2018). Senolytics improve physical function and increase lifespan in old age. Nature Medicine, 24(8), 1246-1256. https://doi.org/10.1038/ s41591-018-0092-9

59. Baker, D. J., Wijshake, T., Tchkonia, T., et al. (2011). Clearance of p16Ink4a-positive senescent cells delays ageing-associated disorders. Nature, 479(7372), 232-236. https://doi.org/10.1038/natur e10600

60. Camell, C. D., Yousefzadeh, M. J., Zhu, Y., et al. (2021). Senolytics reduce coronavirus-related mortality in old mice. Science, 373(6552). doi: https://doi.org/10.1126/science.abe4832.

61. Xu, M., Pirtskhalava, T., Farr, J. N., et al. (2018). Senolytics improve physical function and increase lifespan in old age. Nature Medicine, 24(8), 1246-1256. https://doi.org/10.1038/ s41591-018-0092-9

62. Kirkland, J. L., Tchkonia, T., Zhu, Y., et al. (2017). The clinical potential of Senolytic drugs. Journal of the American Geriatrics Society, 65(10), 2297-2301. https://doi.org/10.1111/jgs.14969

63. Ellison-Hughes, G. M. (2020). First evidence that senolytics are effective at decreasing senescent cells in humans. EBioMedicine, 56, 102473. https://doi.org/10.1016/j.ebiom.2019.09.053 
64. Kirkland, J. L., \& Tchkonia, T. (2020). Senolytic drugs: From discovery to translation. Journal of Internal Medicine, 288(5), 518536. https://doi.org/10.1111/joim.13141

65. Justice, J. N., Nambiar, A. M., Tchkonia, T., et al. (2019). Senolytics in idiopathic pulmonary fibrosis: Results from a first-in-human, open-label, pilot study. EBioMedicine, 40, 554-563. https://doi.org/ 10.1016/j.ebiom.2018.12.052

66. Bell, C. G., Lowe, R., Adams, P. D., et al. (2019). DNA methylation aging clocks: Challenges and recommendations. Genome Biology, 20(1), 249. https://doi.org/10.1186/s13059-019-1824-y

67. Lu, Y., Brommer, B., Tian, X., et al. (2020). Reprogramming to recover youthful epigenetic information and restore vision. Nature, 588(7836), 124-129. https://doi.org/10.1038/s41586-020-2975-4

68. He, X., Liu, J., Liu, B., et al. (2021). The use of DNA methylation clock in aging research. 246(4), 436-446. doi: https://doi.org/10. $1177 / 1535370220968802$.

69. Cole, J. J., Robertson, N. A., Rather, M. I., et al. (2017). Diverse interventions that extend mouse lifespan suppress shared age-associated epigenetic changes at critical gene regulatory regions. Genome Biology, 18(1), 58. https://doi.org/10.1186/s13059-017-1185-3

70. Wang, T., Tsui, B., Kreisberg, J. F., et al. (2017). Epigenetic aging signatures in mice livers are slowed by dwarfism, calorie restriction and rapamycin treatment. Genome Biology, 18(1), 57. https://doi. org/10.1186/s13059-017-1186-2

71. Lopez-Otin, C., Blasco, M. A., Partridge, L., et al. (2013). The hallmarks of aging. Cell, 153(6), 1194-1217. https://doi.org/10.1016/j. cell.2013.05.039

72. Kennedy, B. K., Berger, S. L., Brunet, A., et al. (2014). Geroscience: Linking aging to chronic disease. Cell, 159(4), 709-713. https://doi. org/10.1016/j.cell.2014.10.039

73. Gems, D., \& de Magalhaes, J. P. (2021). The hoverfly and the wasp: A critique of the hallmarks of aging as a paradigm. Ageing Research Reviews, 70, 101407. https://doi.org/10.1016/j.arr.2021.101407

74. Ferrannini, E., Vichi, S., Beck-Nielsen, H., et al. (1996). Insulin action and age: European Group for the Study of insulin resistance (EGIR). Diabetes, 45(7), 947. https://doi.org/10.2337/diab.45.7.947

75. Cypess, A. M., Lehman, S., Williams, G., et al. (2009). Identification and importance of brown adipose tissue in adult humans. The New England Journal of Medicine, 360(15), 1509-1517. https://doi.org/ 10.1056/NEJMoa0810780

76. Masternak, M. M., Panici, J. A., Bonkowski, M. S., et al. (2009). Insulin sensitivity as a key mediator of growth hormone actions on longevity. Journals of Gerontology Series a-Biological Sciences and Medical Sciences, 64(5), 516-521. https://doi.org/10.1093/gerona/ glp024

77. Bartke, A., Brannan, S., Hascup, E., et al. (2021). Energy metabolism and aging. World J Mens Health, 39(2), 222-232.

78. Grunewald, M., Kumar, S., Sharife, H., et al. Counteracting agerelated VEGF signaling insufficiency promotes healthy aging and extends life span. Science, 373(6554), eabc8479. https://doi.org/10. 1126/science.abc8479

79. Avolio, R., Bechara, E., \& Tartaglia, G. G. (2021). The quest for long non-coding RNAs involved in aging. Nature Aging, 1(5), 418-419. https://doi.org/10.1038/s43587-021-00069-9

80. Kim, S. S., \& Lee, S. V. (2019). Non-coding RNAs in Caenorhabditis elegans aging. Molecules and Cells, 42(5), 379-385. https://doi. org/10.14348/molcells.2019.0077

81. Zhou, Q., Wan, Q., Jiang, Y., et al. (2020). A landscape of murine long non-coding RNAs reveals the leading Transcriptome alterations in adipose tissue during aging. Cell Reports, 31(8), 107694. https:// doi.org/10.1016/j.celrep.2020.107694

82. Victoria, B., Dhahbi, J. M., Nunez Lopez, Y. O., et al. (2015). Circulating microRNA signature of genotype-by-age interactions in the long-lived Ames dwarf mouse. Aging Cell, 14(6), 1055-1066. https://doi.org/10.1111/acel.12373

83. Schneider, A., Matkovich, S. J., Victoria, B., et al. (2017). Changes of ovarian microRNA profile in long-living Ames dwarf mice during aging. PLoS One, 12(1), e0169213. https://doi.org/10.1371/journal. pone. 0169213

84. Victoria, B., Nunez Lopez, Y. O., \& Masternak, M. M. (2017). MicroRNAs and the metabolic hallmarks of aging. Molecular and Cellular Endocrinology. https://doi.org/10.1016/j.mce.2016.12.021

85. Zang, Y., Song, J. H., Oh, S. H., et al. (2020). Targeting NLRP3 Inflammasome reduces age-related experimental alveolar bone loss. Journal of Dental Research, 99(11), 1287-1295. https://doi.org/10. 1177/0022034520933533

86. Navarro-Pando José, M., Alcocer-Gómez, E., Castejón-Vega, B., et al. Inhibition of the NLRP3 inflammasome prevents ovarian aging. Science Advances, 7(1), eabc7409. https://doi.org/10.1126/ sciadv.abc7409

87. Youm, Y. H., Grant, R. W., McCabe, L. R., et al. (2013). Canonical Nlrp3 inflammasome links systemic low-grade inflammation to functional decline in aging. Cell Metabolism, 18(4), 519-532. https://doi.org/10.1016/j.cmet.2013.09.010

88. Spadaro, O., Goldberg, E. L., Camell, C. D., et al. (2016). Growth hormone receptor deficiency protects against age-related NLRP3 inflammasome activation and immune senescence. Cell Reports, 14(7), 1571-1580. https://doi.org/10.1016/j.celrep.2016.01.044

89. Camell, C. D., Günther, P., Lee, A., et al. (2019). Aging induces an Nlrp3 Inflammasome-dependent expansion of adipose B cells that impairs metabolic homeostasis. Cell Metabolism, 30(6), 1024-1039. e1026. https://doi.org/10.1016/j.cmet.2019.10.006

90. Hine, C., Yang, J., Bithi, N., et al. (2018). Aging and nutrient availability impact hydrogen sulfide production and sulfhydrome profiles. Innovation. Aging, 2(suppl_1), 878-878. https://doi.org/10.1093/ geroni/igy031.3278

91. Hine, C., Kim, H.-J., Zhu, Y., et al. (2017). Hypothalamic-pituitary Axis regulates hydrogen sulfide production. Cell Metabolism, 25(6), 1320-1333.e1325. https://doi.org/10.1016/j.cmet.2017.05.003

92. Wang, W.-j., Cai, G.-y., Ning, Y.-c., et al. (2016). Hydrogen sulfide mediates the protection of dietary restriction against renal senescence in aged F344 rats. Scientific Reports, 6(1), 30292. https://doi. org/10.1038/srep30292

93. Miller, R. A., Harrison, D. E., Astle, C. M., et al. (2007). An aging interventions testing program: Study design and interim report. Aging Cell, 6(4), 565-575. https://doi.org/10.1111/j.1474-9726. 2007.00311.x

94. Nadon, N. L., Strong, R., Miller, R. A., et al. (2017). NIA interventions testing program: Investigating putative aging intervention agents in a genetically heterogeneous mouse model. EBioMedicine, 21, 3-4. https://doi.org/10.1016/j.ebiom.2016.11.038

95. Chesler, E. J., Gatti, D. M., Morgan, A. P., et al. (2016). Diversity outbred mice at 21: Maintaining allelic variation in the face of selection. G3 (Bethesda), 6(12), 3893-3902. https://doi.org/10.1534/g3. 116.035527

96. Miller, R. A., Harrison, D. E., Astle, C. M., et al. (2014). Rapamycin-mediated lifespan increase in mice is dose and sex dependent and metabolically distinct from dietary restriction. Aging Cell, 13(3), 468-477. https://doi.org/10.1111/acel.12194

97. Harrison, D. E., Strong, R., Allison, D. B., et al. (2014). Acarbose, 17-alpha-estradiol, and nordihydroguaiaretic acid extend mouse lifespan preferentially in males. Aging Cell, 13(2), 273-282. https:// doi.org/10.1111/acel.12170

98. Strong, R., Miller, R. A., Antebi, A., et al. (2016). Longer lifespan in male mice treated with a weakly estrogenic agonist, an antioxidant, an alpha-glucosidase inhibitor or a Nrf2-inducer. Aging Cell. https:// doi.org/10.1111/acel.12496

Publisher's Note Springer Nature remains neutral with regard to jurisdictional claims in published maps and institutional affiliations. 